DEP.IR'AMHNTO DF MICROBIOLOCIA F IMLXOEOGL

Diretor: Pruf. Dr. Paulo M. Ci. de Isacerda Jr.

\title{
ESTUDOS SOBBRE AS MASTITES BOVINAS \\ I - Contribuição ao estudo dos agentes etiológicos das mastites bovinas $\left(^{*}\right)$
}

STUDIES ON BOVINE MASTITIS

I - Ubservations on the causative agents of bovine mastitis

Pat:Lo M. G. de lacerda Jr.

\author{
LIIZ. ZaNi NETO \\ D. C. DE Freitis \\ Assistente \\ Assistente
}

\section{GENER IIIDADFS}

lintre as infeções das vacas leiteiras, as mastites, indiscutivelmente. orupam um lugar de destaque. Encaradas sob o aspecto econômico são muitíssimo prejudiciais, pois, reduzem, quando não eliminam totalmente, a principal função da vaca leiteira: a produção de leite. Encaradas sob o aspecto infeccioso, บุื̃o muitissimo perigosas, pois em sua maioria, os microorganismos encontrados atualmente nas mastites bovinas são patogênicos para o homem, principalmente le vando-se em conta ser o leite alimento infantil por excelência.

O leite pasteurizado não apresenta tais riscos e todo êle deveria ser submetido a êsse tratamento, porém, sabcmos que assim não o é, e infelizment existem cidades do interior que não possuem usinas para pasteurização do lcile.

Lin outro problema é representado pelos leiteiros clandestinos, procuiados por pais menos esclarecido, que, pensando fazer bem a seus filhos, fornec.m. Ihes exatamente o leite menos higiênico e que maiores perigos oferece.

$\mathrm{Na}$ verdade está disseminado o bom hábito de só ser usado leite fervido, mas, em sorvetes, refrescos, êle é ingerido crú.

$\mathrm{Na}$ literatura de outros países, numerosas são as pesquisas sôbre maslites. Entre nós, embora represente a infecção a mesma importância, raríssimos são os trabalhos sôbre o assunto.

Não sabemos com segurança qual a etiologia das mastites de nossas racas leiteiras. Tal verificação é de grande importância atualmente devido ao uso dos antibióticos na terapêutica das mastites. 0 uso indiscriminado de antibióticos, principalmente penicilina e estreptomicina, em tôda e qualquer mastite, tem provocado uma modificação na flora bacteriana das mesmas.

(") Apresentado an II Congresso Pan-Americano de Medicina Veterinária, realinado em São P'aulo, de 3 a 10 de abril de 1954. 
Conforme acentuou Jacquet na $10^{\text {n }}$ Jornada Veterinária D'Alfort, lal fato tem influido numa seleçáo de espécies e varicdades resistentes a êsses antibió. ticos, contribuindo para o desaparecimento de mastites provocadas pelos germes mais sensiveis.

Os microorganismos encontrados por JACQVKT foram: Strep. agalactiar: 60 a $80 \%$; estafilocócos $30 \%$ bacilo coli $1 \%$ e em minima percentagem C. pyo. genes e C. welchi.

Estudando os microorganismos causadores de mastites, SCHMLM, em 1943, encontrou Streplococcus agalactiae em 70 a $90 \%$ dos casos, e Schlotthinek, em 1944, assinalava en 270 microorganismos isolados as seguintes percentagens: estreptocócos 52\%; estafílocócos 34\%; b. coli $8 \%$ e outros germes em peque. nas percentagens.

Em Pôrto Rico, em 1947, Pomains-Lebron e colaboradores, num total de 190 casos, encontraram os seguintes germes: Streptococcus agalactiae 87\%; outros estreptocócos 2,6\%; C. pyogenes 5,8\%; Staphylococcus albus 2,1\%; b. coli e b. piociânico $0,5 \%$.

A incidência dos germes sofre no momento contínua modificação, conforme já comentamos, pelo uso de antibióticos e daí o grande interêsse em estudar-se a atual flora bacteriana das mastites.

Neste estudo, as primeiras amostras de leite de vacas com mastites, confirmaram que a ctiologia no Estado de São Paulo, parece ser diferente da de outros países ou pelo menos sofre no momento significativas modificações. Quanto às variadas causas, que podem influir nessa etiologia, na discussão dos resultados, Jevantaremos diversas hipóteses.

\section{I - MATERIAI ESTUDADO}

Constou de amostras obtidas em propriedades de criação de gado leiteiro, localizadas em municípios vizinhos da Capital (Campinas, Atibaia, Mogi das (ruzes), onde os animais vivem em regime de estabulação ou semi-estabulação, sob contrôle técnico permanente e em condições higiênicas próprias para manutenção de um bom estado hígido.

\section{II - COLETA DO MATLRIAI.}

Tôdas as amostras examinadas foram colhidas por pessoas tècnicamente habilitadas, colegas, ou empregados das propriedades suficientemente esclarecidas para tal fim.

Para isso, fornecíamos frascos esterilizados com capacidade para $20 \mathrm{~cm}^{3}$, onde o material era recolhido após "toilette" das mamas. 
Esses frascos nos eram remetidos no mesmo dia da coleta, a maioria em caminhöes frigoríficos de transporte de leite, e quando isso náo era passível cram conservados em geladeira até o momento da remessa. Em nosfas mãos, cram ciaminados imedialamente. A obtenção de inimeras culturas puras e significatisas. falam em ahôno da técnica empregada.

\section{1 - IE(NICA I)H FXIMF}

Para o exame do material. Lomamos como norma a seguimte orientação:
a) Prova quimica;
b) Microscopia direta;
c) Isolamento dos gernies.

a) Denire as várias provas químicas utilizadas pasa se despistar alteraçöes do leite, em presença de mastite, parlicularmente aquelas recomendadas por TDALL, escolhemos o teste dós cloretos, de HAYDEx, por nos parecer bastante sensivel. Aliás, no material em questäo a maioria das amostras evidenciara al.

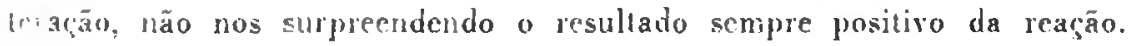

1) O mélodo microscópico direto das amostras, após coloração pelo mélodio de Cram, foi feito com a finalidade de se avaliar a flora existente, o que nos facilitava a marcha das culturas. Sabe-se que muitas vêzes êsse exame microscópico o negativo em se tratando de mastites subclinicas, recomendando-se em lais casos, incubar a amostra durante 24 horas a $37^{\circ} \mathrm{C}$.

kin pnucos casos tivemos necessidade de lançar máo dêsce recurso.

(1) () isolamento de germes obecieceu sempre a um mesmo plano. (O material cra sistemalicamente semeado em três meios líquidos: caldo glicosado, onde se descuvolve bem a generalidade dos germes; caldo bile verde brilhante (Difeo), particularnente recomendado para o grupo coliforme: e caldo-nitrogenelo de sódio-cristal violeta, mejo seletivo para estreplocócos, conforme ficou bem evi. denciado por LACErda, IACEnd \& Frentas, com hase em obserraçōes de HARTMiN, InCHSTEIN \& SNYDEh, e PARker.

Apos um periodo de incuhaçũo de 24 a 18 horas a $37^{\circ} \mathrm{C}$, as culturas eram submetidas a exame microscópico e semeadas em placas. Litilizáramos o agarsangue, para as culturas $\mathrm{cm}$ caldo glicosado e caldo.nitrogeneto de sódio-cristal violeta. Para as culluras que se desenvolviam em caldo bile verde brilhante, utilizávamos o meio "I: M B agar" (B 76 Difco). As colônias desenvolvidas nas placas eram entäo isoladas para estudo de identificação, variando êstes conforme o tipo de germe. Os seguintes esquemas foram empregados: 
1 - Fistafilocicos: observaçăo de pigmento, hemblise e coagulase.

2 - Estreptocucos: hemolise, hidrólise do hipurato de sódio, produção de amónea, açăo sobre a lactose, sorbita e trealosc. Hissa sequência permite reconhecer e diferenciar os principais estreptocócos causadores de mastites.

3 - Coliformes: observağăo em meio de SV e provas bioquimicas de indol. vermclho de metila, Voges \& Proskrauer e utilizaçáo do citrato en meio de Koser. 'l'al processo diferencia tres grupos de coliformes: - grupo Escherichia, o grupo Aerobacter e o grupo ainda näo bem esclarecido dos colifornes intermediários.

4 - O Corynebactarium pyogenes é fàcilmente despistado pelo seu aspecto morfológico e pelo seu desenvolvimento $\mathrm{cm}$ placa de agar sangue.

5 - Uutros germes como difteródes, proteus e prodigiosus nāo ofereceram dificuldade para sua identificação genérica.

\section{CARACIERES'YCAS DAS AMOSTRAS ISOIADAS}

GruPo I - Eslafilocócos.

A diferenciação entre estafilocócos patogênicos - piocócos - e os estafilocócos saprófitas, é de fundamental interêsse para se avaliar da responsabilidade de uma amostra isolada de um processo infeccioso, na etiologia do mesmo. Geralmente os piocúcos são plasmocoagulantes, hemolíticos e fundem ràpidamente a gelatina, propriedades essas pouco encontradas nos saprófitas. Reunimos no quadro abaixo, os resultados das observaçôes de nossas amotras.

QUADKO I - CARACTERILAÇAO DOS FSTAFILOCOCOS

\begin{tabular}{|c|c|c|c|c|c|}
\hline & Сонgulase & I!emolise: & Gelatinase & $\begin{array}{l}\text { Yo de } \\
\text { amostrns }\end{array}$ & lolal \\
\hline$=-$ & $=$ & & $=$ & $=$ & $=$ \\
\hline \multirow{4}{*}{ M. pyogenes var. aureus. } & $t$ & + & + & 12 & \\
\hline & + & - & $t-$ & 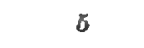 & \\
\hline & - & + & + & 2 & \\
\hline & 一 & - & + & 3 & 22 \\
\hline \multirow[t]{3}{*}{ M. pyngenes var, albus. } & + & + & $+r$ & 3 & \\
\hline & + & 一 & + & 3 & \\
\hline & - & - & + & 6 & 12 \\
\hline \multicolumn{5}{|l|}{ J'otal } & 34 \\
\hline
\end{tabular}

Como vemos, a maioria das amostras por nós isoladas, apresenta proprie. dades de estafilocócos patogênicos, levando-se em conta principalmente a capacidade plasmocoagulante, evidenciada em 23 das 34 amostras. 


\section{Grupo II - Estreplocócos.}

$\mathrm{Na}$ impossibilidade de rlassificar soroligicamenle as amostras de estreptocócos isolados, tculamos uma idenlificação pelas características bioquímicas. que, sem ser complela. perınite reconhecer alguns tipos fundamentais, hem descritos nu clássico tratado de sirlemálica de BrefD, P. S. \& colaboradores (Bergey's Vunual). I nossa atençäo voltara-se, como cra nalural, para o reconhecimento do Streptococcus agalactiae, diante da frequência com que $\mid \mathrm{s}$ gerne é citado na eliologia das mastites. A olscrvaçāo do lipo de hemólise, hidrólise do hipuralo de sídio, produção de amônca e ferncentação da lactose, sorbita c trealose permitiunos distribuir as amostras como se vê no quadro abaixo:

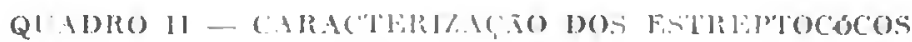

\begin{tabular}{|c|c|c|c|c|c|c|c|}
\hline $\begin{array}{l}N \text { de } \\
\text { ansontras }\end{array}$ & IIcmolise & $\begin{array}{l}\text { Ilipuratos } \\
\text { de súdio }\end{array}$ & Amônex & J,arluse & Soribitx & Irealose & Identificasăo \\
\hline 12 & $\infty \beta$ ou $\gamma$ & + & + & $t$ & - & + & St. agalectine \\
\hline 2 & $\beta$ & - & + & + & + & - & st sooppidemicus \\
\hline 1 & $B$ & - & + & + & - & + & St. oquisimilis \\
\hline 1 & o ou $\gamma$ & $\leftarrow$ & $一$ & + & + & + & st. aoidsmiximus \\
\hline 6 & $\alpha$ our $\gamma$ & - & - & + & \pm & \pm & st. bovis \\
\hline$\downarrow$ & $\alpha$ onl $\gamma$ & - & - & + on - & ‥ ou - & + oil - & Niñ identificados \\
\hline
\end{tabular}

Obsena-se pela distribuiçăo acina, una grande predominância do St. agalactiac, sibbre os demais lipos. As quatro amostras năo identificadas correspondem a lipos cujo comporlamento hiogúmico não se euquadra nos lipos usualmente descritos.

\section{Gripo 111 - Colijormes.}

Este : um oultro grupo de germes cuja classificação é muitas vêzes difícil. 0 agrupamento sorolúgico scria sem dúvida a método ideal de identificação e seria o único capa de reduzir o grupo pouco conhecido dos chamados coliformes internediários. $\mathrm{Na}$ impossibilidade de realizá-lo, empregamos o método bioquímico lançando mão das quatro reaçūes clássicas dos coliformes: produçảo de indol, reação do vermelho de metila, reação de loges \& Proskauer e utilizaçāo do citrato como fonte de carbono. A estas provas foram submetidos todos 
os germes Cram negativos, móveis ou imóveis, fermentadores da lactose, que se desenvolviam em caldo bile verde brilhante c cujas colónias eram tipicas do grupo, em meios diferenciais.

Apresentamos abaixo, un quadro demonstralivo dos reallados oblido:

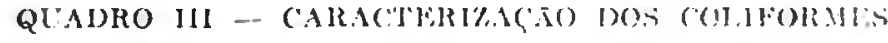

\begin{tabular}{|c|c|c|c|c|c|c|}
\hline $\begin{array}{l}\text { No de } \\
\text { amostra }\end{array}$ & I, actose & Indol & $v$ ii & $\because 1$ & citrieto & Juntificareăo \\
\hline 6 & $A C$ & + & + & $\cdots$ & - & Liseheriehior coli \\
\hline 4 & $A G$ & -- & $\cdots$ & $\dashv$ & + & lerobucier aeroup nes \\
\hline 11 & $A G$ & on - o & $\div \infty 11--$ & $+o u$ & 4 & Coliforme inlernedixisus \\
\hline \multicolumn{6}{|c|}{ Total dos amostras } & 21 \\
\hline
\end{tabular}

Como se observa no quadro acima, há um grance núnero de coliformes que foge dos tipos bem definidos. Esta é, sım dúvida, uma classificação pro. visória, fruto da própria complexidade do grupo em questäo. Estes germes. 10. davia, merecem a nosso ver, muita atenção, cm vista da percentagem em ỵine foram encontrados.

Catpo IV - Corynebacterium pyogenes e hacilos dificróides.

Reunimos neste grupo os bacilos difteruides so $(\therefore$ pyogenes, porque oi primeiros, embora näo permitissem uma identificaçio precisa. ajurescmavam as 'a. racteristicas próprias ao gênero Corynebuctorium.

Gnuro V -. Proteus valgaris, Serratia muresscens e Gram negativos näo ioin. ifficados.

\section{RFSLITADOS}

Alguns dos germes que isolamos de amostras de leite de vacas com mat. tites, não são considerados patogênicos quando na sua localizăţão habilual. hie. ferimo-nos a Escherichia coli, Aerobacter aerogenes e germes do grupo collifor. me. Porém, êsses germes foram isolados $\mathrm{cm}$ cultura pura, de amostras ratu quais, na maioria dos casos, o exame direlo já revelava grande número de $y r$ mes Cran negativos, predominando geralmente um único lipo.

Nas mastites por estafilocócos e estrepiocócos o exame direto tambésil foi hastante elucidativo, principalmente quando se tratava de estrejtocicos, pois sluss longas radeias são características. 
As semeaduras, entretanto, obedeceram sempre un mesmo plano, semeando.se tô?.: as amostras nos três meios liquidos que julganos mais indicados.

Yä i pusice! tratanto-se de germes de mastites, serem feitas provas que compliteden um richo reproduzindo a docnça em animais de tahoraturio. Acre. ditamos. entretanto, que os germes isolados represmicm a hora hacteriane dos rascos por mos estudados.

Yicst: colusho: que consideramos inicial. já podemos antever a importancia

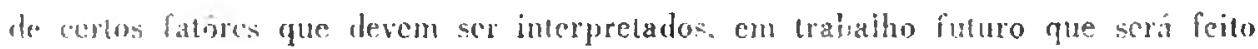

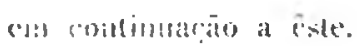

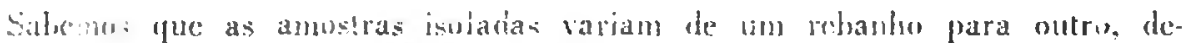

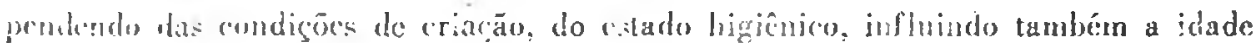

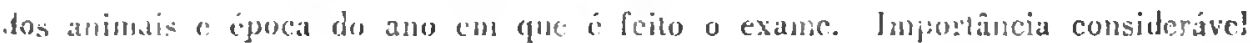

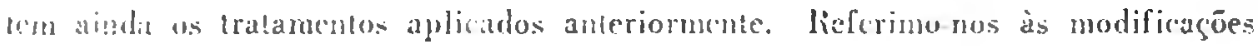

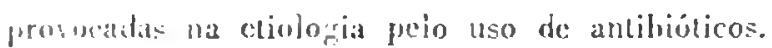

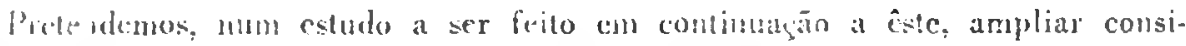
detiselminte o numero de amostras a seren coludadas e contán tôdas as causas gue devenii ser consideradas, conforme experiéncias que adquirimos neste trabalho inicials serāo devidamente: ponderadas.

ie conseguimos executar inteiramente o plano que tcmos en mente, nêle exlarí incluida a coleta de amostras por um dos pesquisadores bacteriologistas.

No muadro IV estão relacionados os germes por nós estudados.

\begin{tabular}{|c|c|c|}
\hline Germes isolitus & Quantidade: & Percentagern \\
\hline Microrocous pmogenes var. aureus $\ldots \ldots \ldots \ldots \ldots \ldots$ & 22 & 20,2 \\
\hline 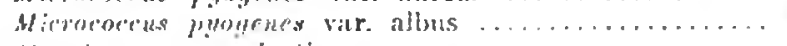 & 12 & 11,4 \\
\hline 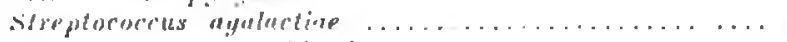 & 12 & 11,4 \\
\hline 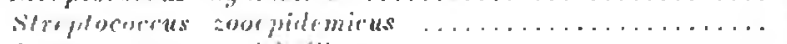 & 2 & 1,9 \\
\hline 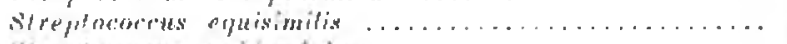 & 1 & $0,9: 5$ \\
\hline 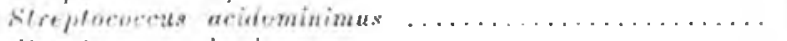 & 1 & 0,95 \\
\hline 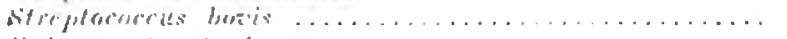 & 6 & 5,7 \\
\hline 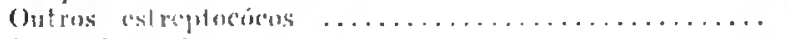 & + & 3.8 \\
\hline 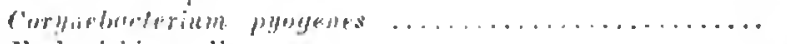 & $\tilde{\imath}$ & 6,6 \\
\hline 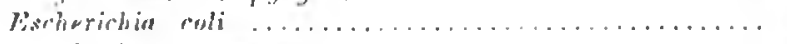 & 6 & 5,7 \\
\hline 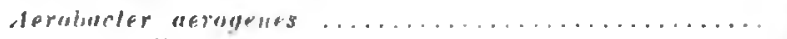 & 4 & $3, \mathbf{3}$ \\
\hline 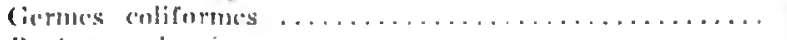 & 11 & I0, +1 \\
\hline 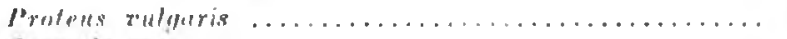 & 3 & 1,9 \\
\hline 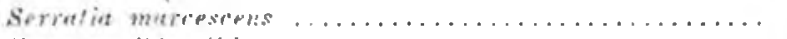 & 1 & 0,95 \\
\hline 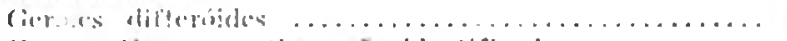 & (i & $5, \pi$ \\
\hline 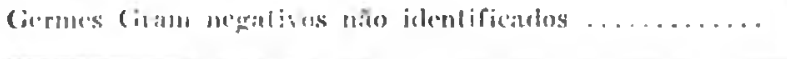 & 8 & 7,6 \\
\hline Tolne dos garmesi & 105 & - \\
\hline
\end{tabular}




\section{DISCLSSAO DOS RESLI.TADOS}

Como já dissemos, é impossivel no estudo dos agentes etiológicos das mas. tites preencher-se o postulado de $\mathrm{Koch}$, reproduzindo-se a doença cm animais de laboratório. Nem sequer é possivel a verificação da patogenicidade dos germes, pois, alguns dos que isolamos são patogênicos ùnicamente devido à localização.

Todavia, são de interêsse prático imediato, os resultados que apresentamos e ora discutimos.

Se analisarmos os germes que isolamos de mastites bovinas veremos que de 88 casos foram isolados 105 microorganismos. Em mais alta percentagem, foram encontrados estafilocócos, sendo que de 34 amostras 2:3 eram positivas na prova da coagulase, a qual, segundo diversos pesquisadores. entre êles Bırr e Chapman, é de valor prático indiscutivel na diferenciação entre os estafilocúcos patogênicos e não patogênicos.

Segundo BELl. \& colaboradores, entretanto, estafilocócos produtores ou não de estafilocoagulose, podem produzir entcrotoxina. Esta seria realmente uma prova de invulgar interêsse, mas é de difícil realização, pois a prova que oferece a maior segurança ć aquela efetuada cm voluntírios humanos. Acreditamos que entre os estafilocicos causadores de mastites, seguramentc existem alguns capazes de cluborar enterotoxina, o que os tornaria extremamente peri. gosos quando em leites empregados no preparo de sorvetes, gelados, etc., os quais, como sabemos, são consumidos principalmente por crianças. Além disso, dado o largo empréco de antibióticos no tratamento das mastites, e a grande facilidade com que os estafilocócos tornam-se resistentes a isses agenles terapicuticos, os germes dessa origem apresentam ainda esse perigo. Fise estudo é Ieito na segunda parte dêste trabalho.

Quantn à frequência das espécies do género Nicrococcus, que arqui comentamos, e gue represcntaram 32.3\% $\%$ do total de nicroorganicmos, não foi ciife.

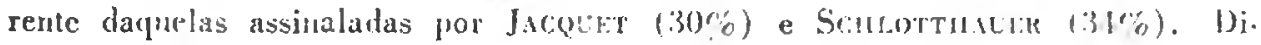

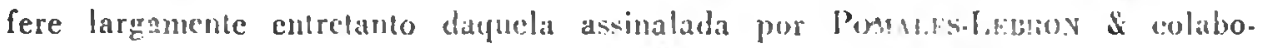
radores que em l'ôrto Rico encontram unicanente 2,1\%o dêse grerme.

Analisando-se o grupo dos estreptococos vîse que isses germes furan por nós encontrados em percentagem bem menor que as comumente assinaladas. Representam êles $24,8 \%$ dos microorganismos por nús isolados, número muito diferente do assinalado por JAcQueT, que encontrou de 60 a $80 \%$ de Sireplococcus ascalactiae. Não assinalou êle outros estreptocócos e, cemo vemos no quadro 11, o Streprococius agalactiac represcnton somente $11,1 \% c$ do tolal de germes. Da mesma forma, Schaly, encontrou o Streptococrus agaluctine em 70

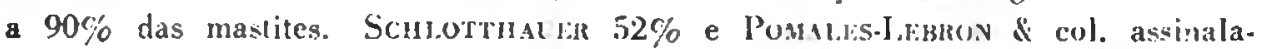
ram $87 \%$. Fistes últimos encontraram ainda 2,65 de outros estreptocócos. Não 
sabemos a que atribuir tal diferença. Muitas das amostras de leite foram co. lhidas de vacas que não apresentavam ainda sintomas de maslites c a suspeita proviuha da prova química positiva. C'ma das propriedades faz prova química diariamcele: do leite de todos os animais o outras fazem semanalmente. Por oulo lado, recebemos também amostras de leite cujo simples exame macroscópico já indicava provir de vacas com mastite.

I.cmbramos que ulilizamos um meio seletivo para os cstreptocúcos. por nós jai hastante usado com hons resiltados, e que loi justamente proposto por IIART. Max para isolamonto de cetrephocícos de mastite hovina.

Quanto an grupo coiliforme, que entra na percentagem de $20 \%$ do tolal de

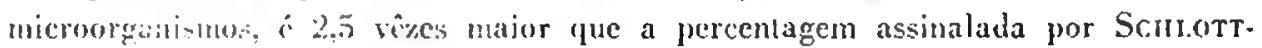

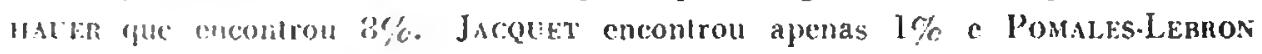
\& col. alsojialarim $], 5 \%$ ré.

Numerosals lippileses poderiam ser levantadas em formo desla iltima discordância de resullados, porém, só a continuação destas observaçós permitiria fazit-las apriadas ("m hases acciávejs. () demais germes encontrados em numero significalivo, foram " Corynebacterium pyogenes em $6,6 \%$ dos casos e b. difteróides em 5.7\%, o $C$. pyogene's i sabido ser um germe encontradiço nas mas. tiles. tenio importância por ser ponco sensivel aos anthiólicus. Com cinco meses de: interialo, já pudemos isolíto do úbere de vacas com mastitc. E' germe yue $\mathrm{cm}$ grunde capacidade para persistir no úbcre hovino.

Quano aus demitis, nada podvmos alvilrar em vista da escassez com quo foran ohicrados. Provicram de úberes infectados, foram oblidos cm culturas puras, mas seu significido etiolúgico e palogênico não pode ser avaliado à vista destes primeiros resultados.

\section{IR F.S 110}

0. aubres estudaram 80 amostras de leite do vacas com mastite, provenientes de: gindo cotabulado e semi-erabulado, de propriedades proximas a cidade

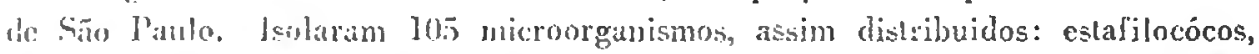
$32.3 \%$; colrptocicos, $28,8 \%$; b. coli e germes do grupo coliforme, 19,9\%;

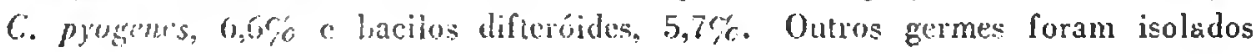
em menor numero. As técnicas empregaras na idemificagán dos microorganis. mos são deriritas e os resultados sĩo discutidos.

\section{STMMTARY}

Anilysic of milk samples collected nearly Säo Paulo city, from 88 cows affected will maslitis have been carried out.

One huidred fine germs could be isolated as follows: 
Staphylucocci, 32.3; Streptococci, 24.8; coli bacillus and other coliforms 19.9\%; Corynebacterium pyogenes, $6.6 \%$; difteroid germs, $5.7 \%$; other typu: of microorganisms have been ohserved in fewer number. The method employid for isolation and identification of the microurganisms have heen deserifued and the results discussed.

\section{LIOGIR,I:II}

B3rst., Wilson 13. et al - 1952- Production of fintervtoxin by Staphylococci Recovered form Bovine Mammary (ilanct. Vet. Med. 47(8):321-22.

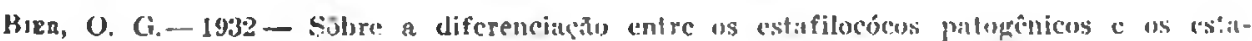
filueúcus dit pele. Mev. Ass. P'ut. Meci, 1:415.

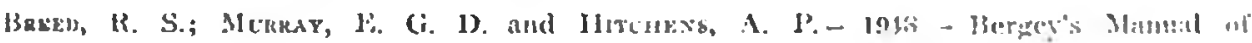

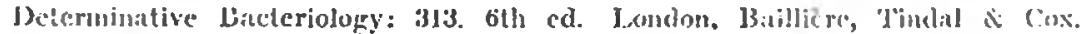

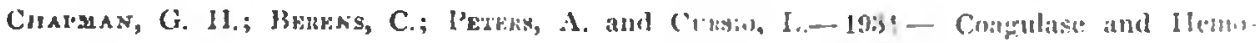

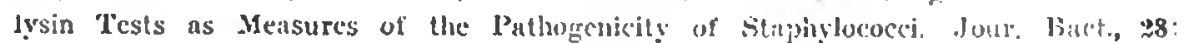
3+3-63.

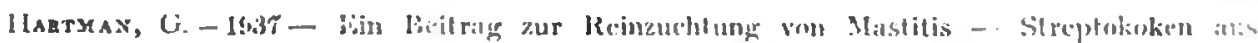
verunreinigen Material. Milchw, Forsch, 18:116-z2 cit. Licstein, Jout. Bact, ty: 6.j3-6.t.

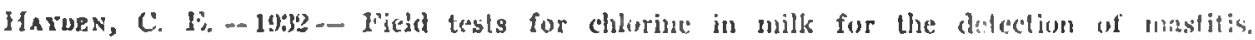
Cornell Vel. 22:277.

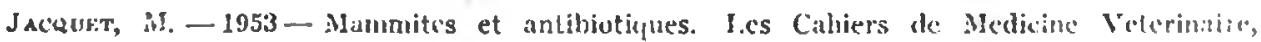
XXII:110-11.

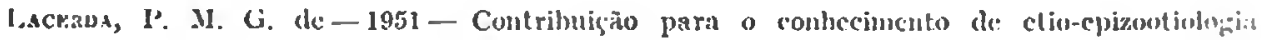

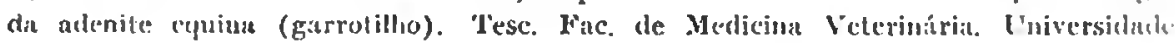
de São l'aulo.

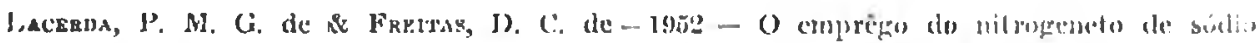

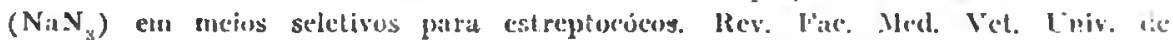
São Patulo, 4:553-57.

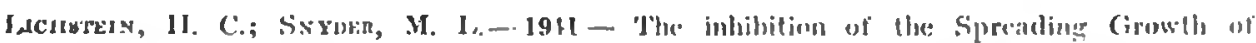
P'ruteus and Other Batcteriat to l'ermit the Isulation of Assuciated Streptomuced. Jour. Bac., 42:653-64.

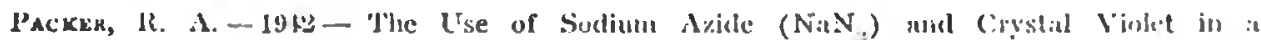

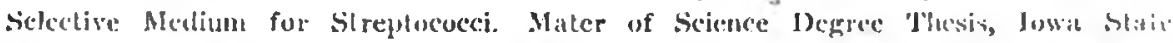

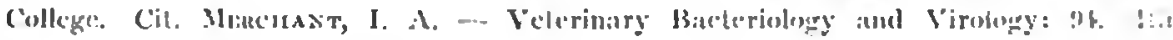
ed. The lenvis state (olllegre l'ress, 1950.

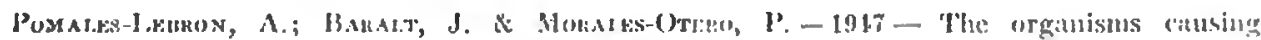
matstitis in l'uerto Rico. Am. Jenur. Vet. laes. 8:338-10.

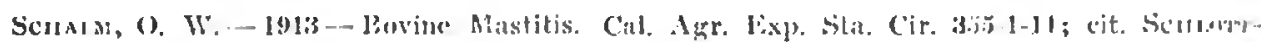

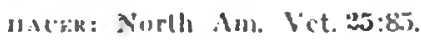

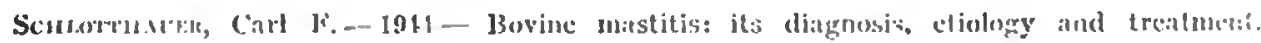
Nortl . Im. Vict. $25: 84-90$.

Cunst., 1). 11. - 1918 - Ille Pratelice of Veterinary Reclicina. th. ed. 1thaca, New York 